\title{
Implicit memory for novel conceptual associations in amnesia
}

\author{
MIEKE VERFAELLIE, ELIZABETH MARTIN, KATIE PAGE, and ELIZABETH PARKS \\ Boston Department of Veterans Affairs, Boston, Massachusetts \\ and Boston University School of Medicine, Boston, Massachusetts \\ and \\ MARGARET M. KEANE \\ Boston Department of Veterans Affairs, Boston, Massachusetts \\ Boston University School of Medicine, Boston, Massachusetts \\ and Wellesley College, Wellesley, Massachusetts
}

\begin{abstract}
In two experiments, we evaluated the status of implicit memory for novel associations in amnesia. Experiment 1 assessed priming in a category exemplar generation task in which contextual information associated with a target could increase the likelihood of target generation. Control participants, but not amnesic patients, showed associative priming. Amnesics' impairment was not due to the use of explicit memory by control subjects but reflected a genuine impairment in implicit memory for novel conceptual associations. Experiment 2 assessed priming in a relatedness judgment task, in which associative priming was manifest as longer latencies for old than for recombined pairs of unrelated words. Amnesic patients showed intact associative priming in this task. We discuss differences in the status of implicit memory for novel conceptual associations in amnesia, with reference to the nature of the representation that supports priming in the two tasks and the type of processing that is required at test.
\end{abstract}

An influential view of hippocampal functioning is that the hippocampus subserves relational (Eichenbaum, 1999) or configural (O’Reilly \& Rudy, 2001) learning mechanisms that are critical for binding together the disparate pieces of information that make up an integrated memory trace of an event. Substantial evidence in support of this view is now available from lesion and neuroimaging studies. For instance, amnesic patients with medial temporal lobe lesions perform disproportionately worse on explicit memory tasks requiring memory for an association between items than on tasks requiring memory for individual items (Giovanello, Verfaellie, \& Keane, 2003; Turriziani, Fadda, Caltagirone, \& Carlesimo, 2004). Similarly, neuroimaging studies have reported greater hippocampal activation during associative than during item-based encoding (Davachi \& Wagner, 2002; Henke, Buck, Weber, \& Wieser, 1997; Henke, Weber, Kniefel, Wieser, \& Buck, 1999) and during associative than during item-based retrieval (Giovanello, Schnyer, \& Verfaellie, 2004; Yonelinas, Hopfinger, Buonocore, Kroll, \& Baynes, 2001).

Much of the research performed to evaluate the role of the hippocampus in relational memory has focused on explicit memory for newly acquired associations. Therefore,

This research was supported by NINDS Grant NS26985, NIMH Grant MH57681, and the Medical Research Service of the Department of Veterans Affairs. Correspondence concerning this article should be addressed to M. Verfaellie, Memory Disorders Research Center, Boston VA Healthcare System, 150 S. Huntington Avenue, Boston, MA 02130 (e-mail: verf@bu.edu). although it is apparent that the hippocampus is critical for the formation of representations that support explicit memory for novel associations, it is less clear whether and under what conditions the hippocampus is also critical for the formation of representations that support implicit memory for novel associations. A potentially important line of evidence pertaining to this question has come from studies in which implicit memory for newly formed associations in amnesia has been evaluated. In such studies, priming for novel associations has been evaluated by comparing performance in a test phase for word (or picture) pairs that had been presented as pairs in the study phase (old pairs) and for pairs for which both elements had been presented in the study phase, but not as part of the same pair (recombined pairs).

To date, studies evaluating new associative priming in amnesia have yielded mixed results. On the one hand, several studies have shown intact priming for novel word pairs in amnesic patients, using tasks that require identification of briefly presented word pairs (Gabrieli, Keane, Zarella, \& Poldrack, 1997; see also Musen \& Squire, 1993) or speeded identification in the form of reading or lexical decision (Goshen-Gottstein, Moscovitch, \& Melo, 2000; Moscovitch, Winocur, \& McLachlan, 1986). On the other hand, several stem completion studies have shown impaired priming for new verbal associations in amnesia (Cermak, Bleich, \& Blackford, 1988; Mayes \& Gooding, 1989; Schacter \& Graf, 1986b; Shimamura \& Squire, 1989).

In an attempt to accommodate these contradictory findings, we have suggested that the status of new associative 
priming in amnesia (and by inference, the role of the hippocampus in forming associations that support implicit memory) critically depends on the nature of the association that is established (Verfaellie \& Keane, 2001, 2002). Specifically, we proposed that amnesic patients may show normal priming for novel perceptual associations but impaired priming for novel conceptual associations (Roediger, Srinivas, \& Weldon, 1989). Associative priming in perceptual identification and lexical decision-both of which are preserved in amnesia - do not require establishment of a conceptual link but depend on establishment of a perceptual link and, thus, provide examples of priming for novel perceptual associations. Confirming the perceptual basis of associative priming in lexical decision, GoshenGottstein and Moscovitch (1995a, 1995b) demonstrated that such priming is sensitive to a shift in perceptual modality, but not to a manipulation of depth of processing. By contrast, new associative priming in the stem completion task, which is impaired in amnesia, depends on the establishment of a meaningful link between the words at study (Schacter \& Graf, 1986a) and is, therefore, conceptual in nature. Findings from the stem completion task, however, need to be interpreted with caution, since associative priming in that task is sometimes unreliable even in normal participants (Cermak et al., 1988).

The purpose of the present study was to evaluate further the status of implicit memory for new conceptual associations in amnesia, using tasks that lead to robust associative priming in normal individuals. We evaluated priming in two tasks: a category exemplar generation task that was adapted to assess associative priming by incorporating contextual information on each trial and a relatedness judgment task in which participants judged whether pairs of words were related in meaning (Goshen-Gottstein \& Moscovitch, 1995a). Both of these tasks require analysis of stimulus meaning and are, therefore, considered to be conceptual in nature; yet they also differ in their response demands (generation vs. classification). It has been suggested in the context of studies of single-item priming that generation and classification tasks may be mediated by distinct conceptual-priming mechanisms (Vaidya et al., 1997). This suggestion is supported by evidence from studies of normal cognition (Vaidya et al., 1997), as well as by studies of neuropsychological populations (Fleischman \& Gabrieli, 1998). Because it is possible that associative priming in these two types of tasks also depends on distinct priming mechanisms, the present study included both a generation task and a classification task in order to assess the status of conceptual associative priming in amnesia.

\section{EXPERIMENT 1A}

To adapt the category exemplar generation task so as to assess new associative priming, we used a design similar to that used in previous word stem completion studies of associative priming. During the study phase, participants were exposed to a series of word pairs in which the first word served as the context word and the second word as the target (e.g., moss-newspaper; banana-airplane). Dur- ing the test phase, the participants were presented with a context word and were asked to generate the first four exemplars of a specified category that came to mind when hearing the context word. On some trials, the context word and category prompt corresponded to a studied word pair (old condition; e.g., moss-reading material?), whereas on other trials, the context word and category prompt corresponded to words that had occurred in different word pairs at study (recombined condition; e.g., moss-vehicle?). A higher proportion of target generations in the old than in the recombined condition would be evidence of implicit memory for the novel association established at study. We also included trials in which both the context word and the category prompt were new (new condition). The comparison between the recombined and the new conditions provided a measure of single-item priming. In line with previous studies of single-item priming in the category exemplar task, we predicted that item priming would be intact in amnesic patients (Graf, Shimamura, \& Squire, 1985; Keane et al., 1997). More important, we predicted that associative priming would be impaired because the exemplar generation task assesses implicit memory for a novel conceptual association between the context word and the target. In parallel with the implicit category exemplar generation task, an explicit category-cued recall task was also administered to verify amnesics' impairment in explicit memory.

\section{Method}

Participants. Twenty amnesic individuals (12 of them male, 8 female) participated in this experiment. Six had a diagnosis of Korsakoff syndrome, whereas the remaining 14 patients had a variety of nonalcoholic etiologies, including anoxia $(n=9)$, encephalitis $(n=3)$, bithalamic stroke $(n=1)$, and anterior communicating artery aneurysm $(n=1)$. No lesion information was available for the Korsakoff patients, but they were presumed to have diencephalic damage, on the basis of etiology. The anoxic and encephalitic patients had documented or presumed damage to medial temporal lobe structures. Demographic and neuropsychological characteristics, as well as lesion information, for individual patients is provided in Table 1 . The combined amnesic group had a mean age of 57 years, a mean education of 14.3 years, and a mean verbal IQ score of 101.5, as measured by the Wechsler Adult Intelligence Scale-III (WAISIII; Wechsler, 1997a). Their attentional abilities, as measured by the Wechsler Memory Scale-III (WMS-III; Wechsler, 1997b) Working Memory Index were also intact, as indicated by a mean score of 96.3. Their memory functioning was severely compromised, as indicated by a mean General Memory Index of 59.4, a mean Visual Delay Index of 65.0, and a mean Auditory Delay Index of 61.3.

The control group consisted of 21 participants $(9$ of them male, 12 female), who had been screened using an extensive health questionnaire. Six control participants had a history of alcoholism and served as controls for the Korsakoff amnesic patients, whereas 15 individuals without a history of alcoholism served as controls for the non-Korsakoff amnesic patients. The participants with a history of alcoholism had abstained from alcohol for at least 3 months prior to taking part in the experiment. The control group was matched to the amnesic group in terms of age $(M=58$ years $)$, education $(M=$ 14.2 years $)$, and WAIS-III Verbal IQ $(M=104.3$; all $t \mathrm{~s}<1)$.

Materials. Two exemplars from each of 36 categories were selected, with the proviso that neither exemplar was the most often generated exemplar for its category (Battig \& Montague, 1969). From these exemplars, two lists of target stimuli were created, con- 
Table 1

Demographic and Neuropsychological Characteristics of Amnesic Participants

\begin{tabular}{|c|c|c|c|c|c|c|c|c|c|c|}
\hline \multirow[b]{2}{*}{ Patient } & \multirow[b]{2}{*}{ Etiology } & \multirow[b]{2}{*}{ Lesion } & \multirow[b]{2}{*}{ Experiment } & \multirow[b]{2}{*}{ Age } & \multicolumn{2}{|c|}{ WAIS-III } & \multicolumn{4}{|c|}{ WMS-III } \\
\hline & & & & & Edu & VIQ & GM & VD & $\mathrm{AD}$ & WM \\
\hline $\mathrm{DNC} 01$ & Korsakoff syndrome & NA & $1 \mathrm{~A}, 2 \mathrm{~A}, 2 \mathrm{~B}$ & 49 & 14 & 80 & 57 & 72 & 58 & 69 \\
\hline $\mathrm{DNC} 02$ & Korsakoff syndrome & NA & $1 \mathrm{~A}$ & 76 & 14 & 99 & 59 & 65 & 58 & 115 \\
\hline DNC03 & Korsakoff syndrome & NA & $1 \mathrm{~A}, 2 \mathrm{~A}, 2 \mathrm{~B}$ & 56 & 12 & 97 & 66 & 62 & 74 & 108 \\
\hline DNC04 & Korsakoff syndrome & NA & $1 \mathrm{~A}, 2 \mathrm{~A}, 2 \mathrm{~B}$ & 82 & 14 & 105 & 66 & 62 & 64 & 121 \\
\hline DNC05 & Korsakoff syndrome & NA & $1 \mathrm{~A}, 2 \mathrm{~A}, 2 \mathrm{~B}$ & 53 & 18 & 111 & 69 & 72 & 64 & 81 \\
\hline DNC06 & Korsakoff syndrome & NA & $1 \mathrm{~A}$ & 48 & 12 & 97 & 59 & 72 & 55 & 91 \\
\hline DNC07 & Korsakoff syndrome & NA & $2 \mathrm{~A}$ & 84 & 9 & 100 & 72 & 75 & 74 & 91 \\
\hline DNC08 & Korsakoff syndrome & NA & $2 \mathrm{~A}, 2 \mathrm{~B}$ & 78 & 14 & 103 & 72 & 68 & 71 & 115 \\
\hline DNC07 & Stroke & bilateral thalamic & $1 \mathrm{~A}, 2 \mathrm{~A}, 2 \mathrm{~B}$ & 59 & 12 & 84 & 73 & 84 & 67 & 99 \\
\hline MTL01 & Anoxia & NA & $1 \mathrm{~A}, 2 \mathrm{~A}, 2 \mathrm{~B}$ & 64 & 20 & 111 & 52 & 56 & 64 & 83 \\
\hline MTL02 & Anoxia & $\mathrm{H}$ & $1 \mathrm{~A}, 2 \mathrm{~A}, 2 \mathrm{~B}$ & 72 & 18 & 113 & 75 & 72 & 80 & 102 \\
\hline MTL03 & Anoxia & $\mathrm{H}+$ & $1 \mathrm{~A}, 2 \mathrm{~A}, 2 \mathrm{~B}$ & 52 & 12 & 83 & 52 & 56 & 55 & 91 \\
\hline MTL04 & Anoxia & $\mathrm{H}+$ & $1 \mathrm{~A}, 2 \mathrm{~A}, 2 \mathrm{~B}$ & 38 & 16 & 86 & 49 & 53 & 52 & 93 \\
\hline MTL05 & Anoxia & $\mathrm{H}$ & $1 \mathrm{~A}$ & 19 & 10 & 91 & 45 & 56 & 46 & 79 \\
\hline MTL06 & Anoxia & $\mathrm{H}$ & $1 \mathrm{~A}, 2 \mathrm{~A}, 2 \mathrm{~B}$ & 43 & 14 & 90 & 45 & 53 & 52 & 93 \\
\hline MTL07 & Anoxia & $\mathrm{H}$ & $1 \mathrm{~A}, 2 \mathrm{~A}, 2 \mathrm{~B}$ & 46 & 14 & 111 & 59 & 72 & 52 & 96 \\
\hline MTL08 & Anoxia & $\mathrm{H}$ & $1 \mathrm{~A}$ & 75 & 12 & 107 & 59 & 65 & 64 & 83 \\
\hline MTL09 & Anoxia & NA & $1 \mathrm{~A}$ & 51 & 17 & 134 & 70 & 75 & 67 & 88 \\
\hline MTL10 & Anoxia & $\mathrm{H}+$ & $2 \mathrm{~A}$ & 24 & 10 & 92 & 45 & 50 & 55 & 81 \\
\hline MTL11 & Encephalitis & $\mathrm{H}+$ & $1 \mathrm{~A}, 2 \mathrm{~A}, 2 \mathrm{~B}$ & 46 & 14 & 92 & 45 & 56 & 55 & 85 \\
\hline MTL12 & Encephalitis & $\mathrm{H}+$ & $1 \mathrm{~A}, 2 \mathrm{~A}, 2 \mathrm{~B}$ & 59 & 12 & 106 & 69 & 68 & 77 & 111 \\
\hline MTL13 & Encephalitis & $\mathrm{H}+$ & $1 \mathrm{~A}, 2 \mathrm{~A}, 2 \mathrm{~B}$ & 74 & 18 & 135 & 45 & 53 & 58 & 141 \\
\hline $\mathrm{ACoA} 01$ & $\mathrm{ACoA}$ aneurysm & $\begin{array}{l}\text { basal forebrain } \\
\text { L frontal }\end{array}$ & $1 \mathrm{~A}$ & 75 & 12 & 98 & 73 & 75 & 64 & 96 \\
\hline
\end{tabular}

Note-WAIS-III, Wechsler Adult Intelligence Scale (Wechsler, 1997a); WMS-III, Wechsler Memory Scale (Wechsler, 1997b); Edu, education in years; VIQ, verbal IQ; GM, general memory index; VD, verbal delay index; AD, auditory delay index; WM, working memory index; DNC, damage to the diencephalic regions; MTL, damage to the medial temporal lobes; ACoA, anterior communicating artery; NA, not available; $\mathrm{H}$, hippocampus; $\mathrm{H}+$, hippocampus and surrounding subhippocampal cortices.

sisting of one exemplar from each category. These lists were used in the implicit and explicit tasks, with assignment of lists counterbalanced across participants. Each target was paired with a unique unrelated word that served as its context word. Two master lists of 36 word pairs thus constructed were matched in terms of frequency of target exemplar production ( $M=272$; Battig \& Montague, 1969), word frequency (Francis \& Kučera, 1982) of the target word $(M=$ $40)$, and word frequency of the context word $(M=39)$.

Each master list of word pairs was divided into three sets of 12, to be rotated through the old, recombined, and new conditions. The three sets were also matched in terms of mean exemplar production frequency, frequency of the target word, and frequency of the context word. Three study forms were created for each master list, each consisting of a different combination of two sets of 12 items. For one set of items, which served to create the old condition, the pairs were kept intact. For the other set of items, which served to create the recombined condition, the context word and target from each pair were randomly rearranged. Pairs were presented pseudorandomly in each study form, with the proviso that no more than 3 items from the same set should occur in a row. Two filler pairs were added to the beginning and end of the study list. There was one test form corresponding to each master list. Each test form comprised 36 trials, on each of which a context word was presented with the category label corresponding to the target word with which the context word was paired in the master list.

Procedure. During the study phase of the implicit and explicit tasks, word pairs (e.g., moss-newspaper) were presented one at a time on the screen, with the context word presented above the target word. The participants were asked to read the words aloud and were then read a statement that related both words (e.g., "adding moss to compost helps decompose newspaper"). They were asked to indicate on a 3-point scale how believable the statement was. The participants responded verbally, and $1,500 \mathrm{msec}$ after their response, the next trial was initiated. During the implicit test phase, on each trial, the participants were given a context word and a category and were asked to generate the first four exemplars of the category that came to mind upon hearing the context word (e.g., "when I say moss, what are the first four types of reading material that come to mind?"). During the explicit test phase, on each trial, the participants were given a context word, followed by a category, and were asked to remember whether an item from that particular category had been on the list of words that they had seen earlier and, if so, to provide that exemplar. They were told that not all the categories had been on the study list and to refrain from answering if they could not remember having seen an exemplar from a particular category.

\section{Results}

Preliminary analyses indicated that the pattern of results did not differ for participants with and without a history of alcohol abuse. Therefore, the results from the two control subgroups were combined, as were the results of the two amnesic subgroups.

Implicit memory. Figure 1 presents the proportion of target words generated by the amnesic and control group in the different test conditions. As can be seen, only the control group showed clear evidence of associative priming, as reflected in the higher rate of target completions in the old than in the recombined condition. In contrast, both groups showed item priming, as evidenced by a higher rate of target completions in the recombined than in the new condition.

Separate analyses, performed on the arcsine-transformed data, were used to evaluate associative and item priming. Associative priming was evaluated in an ANOVA with 


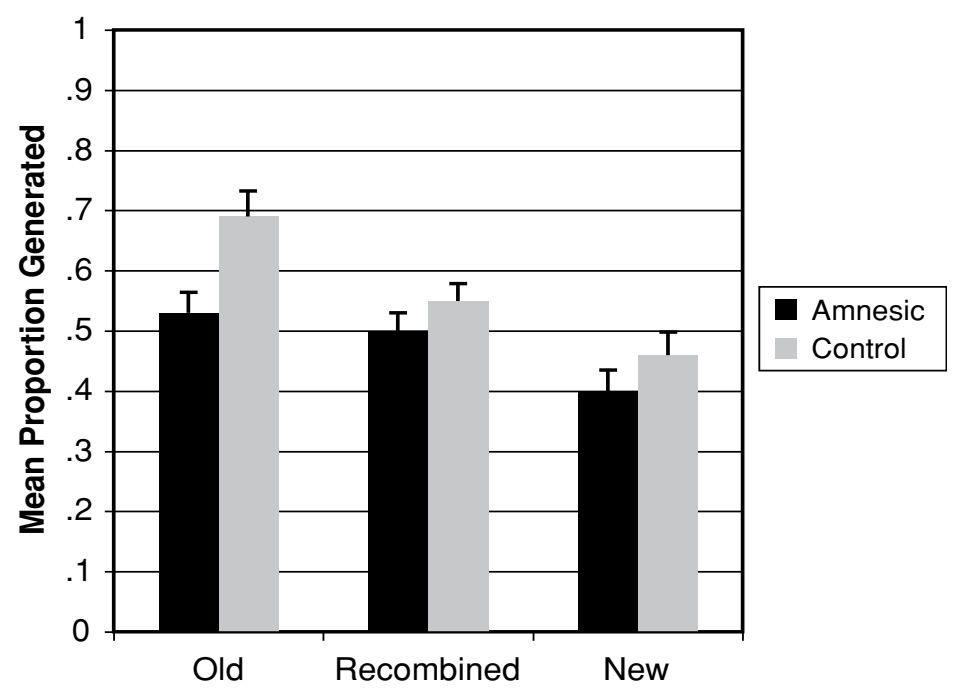

Figure 1. Experiment 1A: Mean proportion of target words generated as a function of test condition.

group as the between-subjects factor and condition (old or recombined) as the within-subjects factor. This analysis revealed a main effect of group $[F(1,39)=9.40, p<$ $.01]$, a main effect of condition $[F(1,39)=7.16, p=.01]$, and a marginal group $\times$ condition interaction $[F(1,39)=$ $3.14, p=.08]$. Associative priming was significant in the control group $[t(20)=3.1, p<.01]$, but not in the amnesic group $[t(19)<1]$. Item priming was evaluated in an ANOVA with group as the between-subjects factor and condition (recombined or new) as the within-subjects factor. This analysis revealed a main effect of condition $[F(1,39)=10.40, p<.01]$. Neither the effect of group $[F(1,39)=1.93]$ nor the group $\times$ condition interaction $[F(1,39)<1]$ was significant.
Explicit memory. Figure 2 presents the proportion of targets recalled by amnesic and control participants in the various conditions. Target responses in the new condition, representing baseline guessing, were minimal in both groups. As was expected, cued recall was poorer in the amnesic group than in the control group, but both groups showed better recall when the context word had previously been studied with the to-be-remembered target (old) than when it had been studied with another target (recombined).

For the purpose of analysis, proportions were arcsine transformed and submitted to an ANOVA with group as the between-subjects variable and condition (old or recombined) as the within-subjects variable. Results of

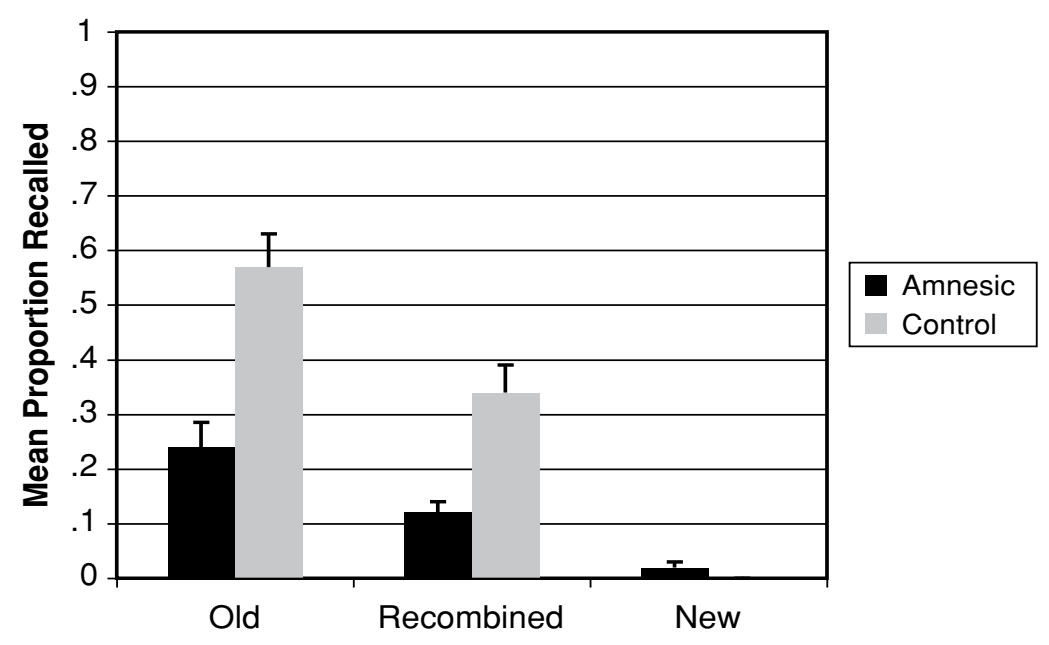

Figure 2. Experiment 1A: Mean proportion of target words recalled as a function of test condition. Items in the old and recombined conditions are recalled following study; items in the new condition reflect baseline guessing. 
the analysis revealed a significant main effect of group $[F(1,38)=21.4, p<.01]$ and a significant effect of condition $[F(1,38)=26.97, p<.01]$, confirming the impressions above. The group $\times$ condition interaction was not significant $[F(1,38)=1.89]$.

\section{Discussion}

In the implicit memory task, the control participants generated more target exemplars when the category cue was presented with the same context word with which the target had been paired at study (old condition) than when it was presented with a different context word (recombined condition), indicating implicit memory for the associative relationship established between the context word and the exemplar during the study phase. Amnesic patients, in contrast, failed to show such associative priming. The amnesic group, however, did show significant single-item priming, as evidenced by their greater rate of generating target exemplars in the recombined condition than in the new condition. Moreover, the magnitude of single-item priming in the amnesic group was similar to that in the control group. Amnesics' selective failure to show associative priming is consistent with the hypothesis that conceptual priming for novel associations is impaired in amnesia and suggests that the establishment of associations that can support conceptual implicit associative memory depends critically on the integrity of the hippocampus.

Before accepting this conclusion, however, it is important to rule out the possibility that associative priming in the control participants was due merely to explicit memory contamination. It is possible that when presented with the category cue in the implicit exemplar generation task, the control subjects intentionally retrieved a target from the study list. Such intentional retrieval would be expected to be more likely and/or more successful in the old condition than in the recombined condition, thus leading to a pattern of performance similar to that characterizing associative priming. If such were the case, the failure of amnesics to show associative priming would not reflect a genuine impairment in implicit associative memory but, rather, a failure to use explicit memory in a nominally implicit task. Experiment 1B was designed to evaluate this possibility.

\section{EXPERIMENT 1B}

In their studies of priming for new associations in the stem completion task, Schacter and Graf (1986a) demonstrated that the type of associative elaboration at encoding sentence rating versus sentence generation-affected explicit memory for novel associations but had no effect on implicit memory for novel associations. The differential effect of the encoding manipulation on explicit and implicit memory allowed them to rule out the possibility that participants used explicit strategies in the implicit test (Schacter, Bowers, \& Booker, 1989). Here, we used a similar encoding manipulation to evaluate whether associative priming in the category exemplar generation task is dissociable from explicit category cued recall.
The control participants in this experiment performed the category exemplar generation and category cued recall task, following a study phase in which they generated sentences containing the context and target word, and their performance was compared with that of the nonalcoholic control participants in Experiment 1A, who performed a sentence-rating task in the study phase.

\section{Method}

Participants. Sixteen normal participants ( 5 of them male, 11 female), who had been screened using an extensive health questionnaire, participated in this experiment. The group was matched to the nonalcoholic control group in Experiment 1A in terms of age ( $M=58$ years), education ( $M=14.4$ years), and WAIS-III Verbal IQ $(M=103.7$; all $t \mathrm{~s}<1)$. The results from 1 female participant were excluded because her sentence generation indicated that several target words were interpreted in a manner different from that intended by the experimenter.

Materials and Procedure. The materials and procedure were identical to those used in Experiment 1A, with the exception of the encoding task used during the study phase. Word pairs were presented one at a time on the screen, with the context word presented above the target word. The participants were asked to read the words aloud and to generate a sentence that meaningfully incorporated both words.

\section{Results}

Figure 3 presents the results for both the implicit and the explicit tasks for the participants in Experiment 1B who generated sentences, as well as for the nonalcoholic control participants in Experiment 1A who generated sentences. As in Experiment 1A, the data were arcsine transformed for the purpose of analysis. First, we analyzed the results from Experiment 1B in isolation. In the implicit task, the participants generated more target exemplars in the old than in the recombined condition $[t(14)=1.61$, $p<.07$, one-tailed]. Similarly, in the explicit task, they recalled more targets in the old than in the recombined condition $[t(14)=4.68, p<.01]$.

Next, we compared implicit test results from Experiments $1 \mathrm{~A}$ and $1 \mathrm{~B}$ in a two-way ANOVA with a betweensubjects factor of encoding task (rating or generation) and a within-subjects factor of condition (old or recombined). This analysis revealed a main effect of encoding task $[F(1,28)=7.10, p<.05]$, indicating that the participants who rated sentences generated more target exemplars than did those who generated sentences during the study phase. There was also a main effect of condition $[F(1,28)=7.17$, $p<.05]$, indicating that more targets were generated in the old condition than in the recombined condition. Importantly, the encoding task $\times$ condition interaction was not significant $[F(1,28)<1]$, indicating that the magnitude of associative priming was similar in the two encoding groups.

Finally, an ANOVA was performed on the explicit test data from Experiments $1 \mathrm{~A}$ and $1 \mathrm{~B}$, with encoding task as the between-subjects factor and condition as the withinsubjects factor. This analysis revealed a main effect of encoding task $[F(1,28)=5.84, p<.05]$, indicating that cued recall was higher in the participants who generated 

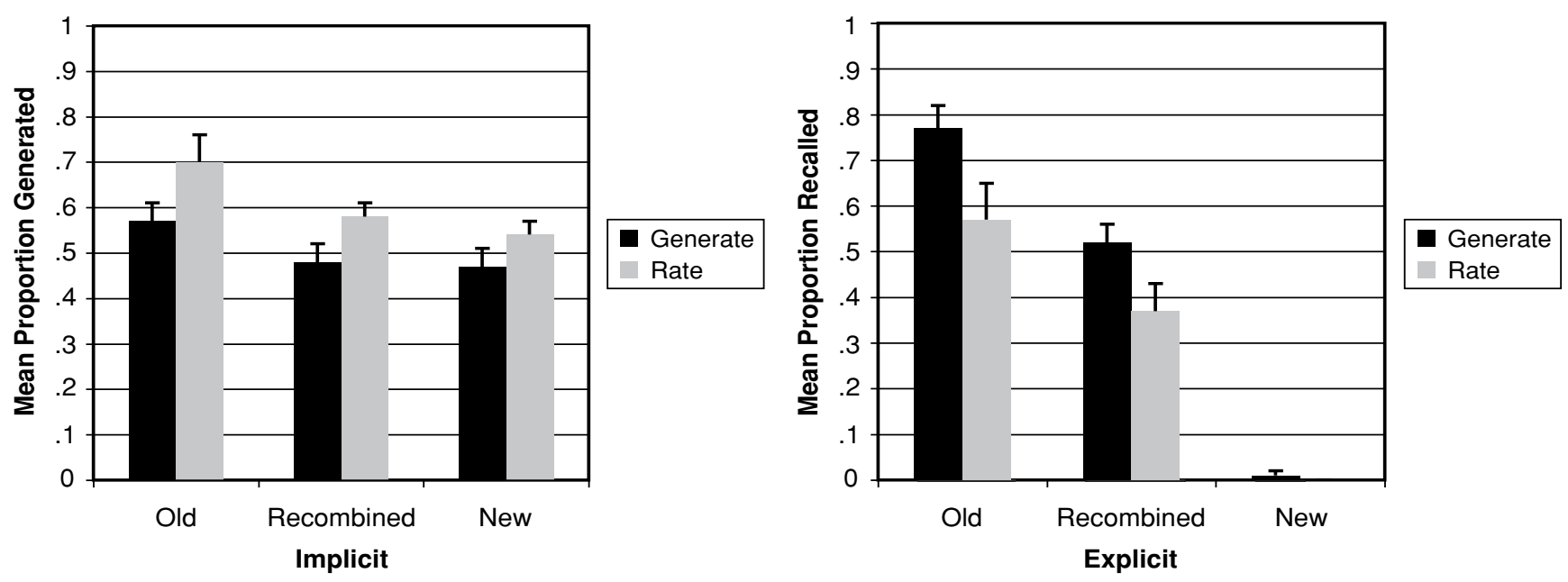

Figure 3. Mean proportion of target words provided in the implicit and explicit tests as a function of test condition for the participants who generated sentences (in Experiment 1B) and for a matched subgroup of participants who rated sentences (in Experiment 1A).

sentences than in those who rated sentences. There was also a main effect of condition $[F(1,28)=32.92, p<.01]$, indicating higher recall in the old than in the recombined condition. The encoding task $\times$ condition interaction was not significant $[F(1,28)<1]$.

To directly compare performance in the implicit and the explicit tests across the two encoding groups, we performed a $2 \times 2 \times 2$ ANOVA with encoding (rating or generation) as the between-groups factor and test (implicit or explicit) and condition (old or recombined) as the withinsubjects factors. In addition to a main effect of condition $[F(1,28)=38.48, p<.01]$, there was a test $\times$ condition interaction $[F(1,28)=4.62, p<.05]$ and a test $\times$ encoding interaction $[F(1,28)=17.39, p<.01]$. The former interaction indicated that the difference between same and different context performance was greater in the explicit test than in the implicit test. More important, the latter interaction indicated that implicit memory performance was higher following rating than following sentence generation, whereas the opposite was true for explicit test performance.

\section{Discussion}

Like sentence rating, sentence generation proved to be an effective encoding task to establish both implicit and explicit memory for new associations. In comparison with sentence rating, sentence generation led to an overall improvement in explicit cued recall, but to a decrement in implicit exemplar generation. The differential effects of encoding on performance in the implicit and explicit memory tasks provide evidence that performance on the implicit category generation task was not due merely to explicit memory contamination. Rather, it indicates that the processes that mediate performance on the two tasks are dissociable.

It should be noted, however, that despite the overall enhancement of explicit memory following sentence generation, the encoding manipulation did not differentially affect performance in the old condition, in comparison with the recombined. The failure to obtain an effect of encoding specifically on the measure of associative explicit memory stands in contrast to the findings of Schacter and Graf (1986a). ${ }^{1}$ Importantly, it leaves unanswered the question as to whether implicit and explicit memory for new associations can be dissociated, since neither was affected by the encoding manipulation. To get further leverage on this question, we examined performance in a subgroup of participants in Experiment 1B who had substantially greater associative explicit memory $(n=7$; old, .84; recombined, .41) than did the nonalcoholic participants in Experiment $1 \mathrm{~A}$ who performed the sentence-rating task. As was expected, an ANOVA comparing cued recall in this subgroup with that in the group who performed sentence rating revealed a significant encoding group $\times$ condition interaction $[F(1,20)=6.44, p<.05]$. Critically, associative implicit memory in this subgroup (old, .56; recombined, .52) was no greater than that in the group who performed the rating task. Confirming this impression, an ANOVA comparing exemplar generation for this subgroup with that for the group who performed sentence rating revealed a marginal effect of encoding group $[F(1,20)=$ $3.77, p<.07]$, with higher completion rates for the participants who performed sentence rating, but no group $\times$ condition interaction $[F(1,20)=1]$. The differential effect of encoding on implicit and explicit associative memory was confirmed in an ANOVA that included test type as a factor. There was a significant interaction between test type, encoding task, and condition $[F(1,20)=6.02, p<$ $.05]$, reflecting the fact that the encoding manipulation affected explicit, but not implicit, associative memory. Thus, the participants in the sentence generation condition, who showed greater associative explicit memory than did those in the sentence-rating condition, nonetheless showed no increase in implicit associative memory (and in fact, showed a nonsignificant decrease), in comparison with the participants in the sentence-rating condition. 
These findings provide more compelling evidence that implicit memory for novel associations in the category exemplar generation task is not contaminated by explicit memory for these associations. Correspondingly, it establishes that amnesics' failure to show associative priming in Experiment $1 \mathrm{~A}$ reflected a genuine impairment in implicit memory for new associations in the context of a generation task. To evaluate the generality of this impairment, Experiment 2 evaluated implicit memory for novel associations in the context of a verification task.

\section{EXPERIMENT 2A}

To evaluate conceptual associative priming in the context of a verification task, we adopted the relatedness judgment task introduced by Goshen-Gottstein and Moscovitch (1995a). Following exposure to related and unrelated word pairs during a study phase, the participants in that study were asked to make speeded relatedness judgments about previously encountered (old) word pairs and recombined word pairs. To assess priming for novel associations, reaction times were evaluated for old and recombined pairs that were unrelated, since only responses to unrelated word pairs provide evidence for the formation of a novel association. Goshen-Gottstein and Moscovitch (1995a) found that "no" responses to old unrelated pairs were slower than "no" responses to recombined unrelated pairs. Thus, associative priming was reflected as a cost in reaction time: The participants were slower to generate a "no" response to previously paired unrelated words than to recombined unrelated words, presumably because they had a harder time inhibiting a "yes" response in the former than in the latter condition (for a similar effect, see Srinivas, Culp, \& Rajaram, 2000). Associative priming for novel associations was not sensitive to modality of presentation, suggesting that it was not perceptually based (Goshen-Gottstein \& Moscovitch, 1995a). Instead, since the relatedness judgment task requires evaluation of the semantic attributes of words, the authors suggested that new associative priming in their task was conceptually based. In the present experiment, this paradigm was used to evaluate priming for novel associations in amnesic patients, with the aim of assessing whether the impairment observed in Experiment 1A in the context of a generation task would extend to a verification task.

\section{Method}

Participants. Seventeen amnesic individuals (12 of them male, 5 female) and 25 participants with intact memory abilities (10 of them male, 15 female) participated in the experiment (see Table 1). Six of the 17 participants had a diagnosis of Korsakoff syndrome, whereas the remaining 11 patients had a variety of nonalcoholic etiologies, including anoxia $(n=7)$, encephalitis $(n=3)$, and bithalamic stroke $(n=1)$. With the exception of 2 Korsakoff patients and 1 anoxic patient, these patients had all participated in Experiment 1A. The combined group of amnesics had a mean age of 58.3 years, with a mean education of 14.2 years. The mean verbal IQ of the patient group, as measured by the WAIS-III, was 99.9. Their attentional abilities, as measured by the WMS-III Working Memory Index, were intact, as indicated by a mean score of 97.7. Their memory functioning was severely compromised, as indicated by a mean General Memory
Index of 59.5, a mean Visual Delay Index of 63.8, and a mean Auditory Delay Index of 63.1.

The control group consisted of 9 individuals with a history of alcoholism and 16 individuals with no known history of alcoholism. All had been screened using an extensive health questionnaire. The control group had a mean age of 56.6 years, with a mean education of 14.5 years and a mean WAIS-III verbal IQ score of 103.5. The control and amnesic participants did not differ significantly in age, education, or verbal IQ (all $t \mathrm{~s}<1$ )

Materials. The stimuli consisted of 44 arrays of four related words, taken from Goshen-Gottstein and Moscovitch (1995a), with the exception of five words that were replaced because they occurred more than once in the stimulus lists. These arrays were divided into four sets of 11. For each participant, two of the sets were used to create related and unrelated pairs presented in the study list, whereas the other two sets were used to create related and unrelated pairs that served as unstudied stimuli in the test list. The assignment of sets to related versus unrelated pairs and studied versus unstudied pairs was counterbalanced across participants.

Each study list consisted of 22 related word pairs and 22 unrelated word pairs. Related word pairs were created by selecting the first two words of an array (R1 and R2) and the last two words of an array (R3 and R4). Unrelated word pairs were created by randomly repairing the first item of an array with the second item of a different array within the same set (U1-U2) and, likewise, by repairing the third item of an array with the fourth item of a different array within the same set (U3-U4).

Each test list consisted of 44 studied word pairs ( 22 related and 22 unrelated) and 44 unstudied word pairs ( 22 related, 22 unrelated). Half of the studied word pairs were presented in their studied pairing (e.g., R1-R2 and U1-U2), whereas the other half were rearranged by pairing the first item of the array with the last item of the array. In this way, recombined pairs were formed, the elements of which were again related (e.g., R1-R4) or unrelated (U1-U4).

Procedure. During the study phase, each trial started with the presentation of a fixation cross for $500 \mathrm{msec}$. This was followed $500 \mathrm{msec}$ later by presentation of two words side by side for $5 \mathrm{sec}$. The participants were asked to read each word aloud and to make a meaningful sentence that related both words in their stated order. During the test phase, each trial consisted of presentation of a fixation cross for $500 \mathrm{msec}$, followed by presentation of the word pairs side by side. The participants were asked to determine whether the two words were related or unrelated. They were told that two words were to be considered related if they had a strong link between them, if they belonged to the same category, or if the two words were often seen or spoken together. Their response was recorded using a twobutton response box, and they were asked to respond as quickly and accurately as possible. Stimuli remained on the screen until a response was made, and the next trial was initiated $500 \mathrm{msec}$ later.

\section{Results}

Because only the results from unrelated word pairs speak to the status of new associative priming in amnesia, the analysis was restricted to those items. Preliminary analyses indicated that the pattern of results did not differ for the participants with and without a history of alcohol abuse. Therefore, the results from the two control subgroups were combined, as were the results of the two amnesic subgroups.

As a group, the amnesic participants $(M=92.6 \%)$ were less accurate at making relatedness judgments than were the control participants $[M=95.6 \%, t(40)=3.06, p<$ $.01]$. Because latency data were analyzed only for correct trials, and to ensure a sufficient number of observations per condition, the analysis was restricted to those partici- 
pants whose accuracy was at least $80 \%$ in each condition. This resulted in elimination of the results of 4 amnesic patients and 1 alcoholic control subject.

As can be seen in Figure 4, decision latencies in the amnesic group were longer and more variable than those in the control group. Nonetheless, the pattern of RTs as a function of condition was similar in the two groups. In both groups, RTs to old pairs were longer than those to recombined pairs, reflecting the presence of an associative priming effect. Also, in both groups, RTs to new pairs were longer than those to recombined pairs, although this item priming effect was very small in the control group.

Analyses were performed on log-transformed data to evaluate each type of priming separately. To evaluate associative priming, we performed an ANOVA with group as the between-subjects factor and condition (old or recombined) as the within-subjects factor. There was a main effect of group $[F(1,35)=6.04, p<.05]$ and a main effect of condition $[F(1,35)=13.13, p<.01]$. In addition, there was a marginal group $\times$ condition interaction $[F(1,35)=$ $3.00, p<.10]$, which indicated that, if anything, associative priming was greater in the amnesic group than in the control group. ${ }^{2}$ To evaluate item priming, we performed an ANOVA with group as the between-subjects factor and condition (recombined or new) as the within-subjects variable. The results of this analysis revealed a main effect of group $[F(1,35)=6.73, p<.05]$, a marginal effect of condition $[F(1,35)=2.87, p<.10]$, and a marginal group $\times$ condition interaction $[F(1,35)=2.87, p<.10]$. Item priming was significant in the amnesic group $[t(12)=$ $2.40, p<.05]$, but not in the control group $[t(23)<1]$.

\section{Discussion}

The amnesic patients, like the controls, were slower in judging that unrelated word pairs were not semantically related when the words constituting the pair had previously been seen together than when they had been seen as components of different word pairs. Moreover, this inhibitory effect, which constitutes evidence of associative priming, was as large in the amnesic patients as in the controls. Amnesics' ability to form novel conceptual associations that can support performance in a verification task is striking, especially in light of their impaired associative priming in the category exemplar generation task. However, the significance of this dissociation rests, in part, on the assumption that explicit memory for these associations will be impaired when tested in the context of a verification (recognition) task, just as it was in the context of a generation (cued recall) task. In Experiment 2B, we evaluated whether this was indeed the case.

\section{EXPERIMENT 2B}

To assess explicit memory for novel associations in the context of a verification task, we administered a recognition memory task, using study and test presentations that were analogous to those in Experiment 2A. Following exposure to related and unrelated word pairs during a study phase, the participants were asked to make recognition judgments about previously encountered (old), recombined, and novel word pairs. They were asked to endorse only those word pairs for which both words had been seen together in the study phase.

\section{Method}

Participants. Fourteen amnesic individuals (10 of them male, 4 female) and 14 participants with intact memory abilities ( 4 of them male, 10 female), all of whom had participated in Experiment 2A, were available for participation in this experiment. Five of the amnesic participants had a diagnosis of Korsakoff syndrome, and 9 had a variety of nonalcoholic etiologies ( 5 anoxia, 3 encephalitis, and 1 bithalamic stroke). The combined group of amnesics had a mean age of 60.2 years, with a mean education of 15 years. The mean verbal IQ of the patient group, as measured by the WAIS-III, was 101.7. Their attentional abilities, as measured by the WMS-III Working Memory Index, were intact, as indicated by a mean score of 99.8 .

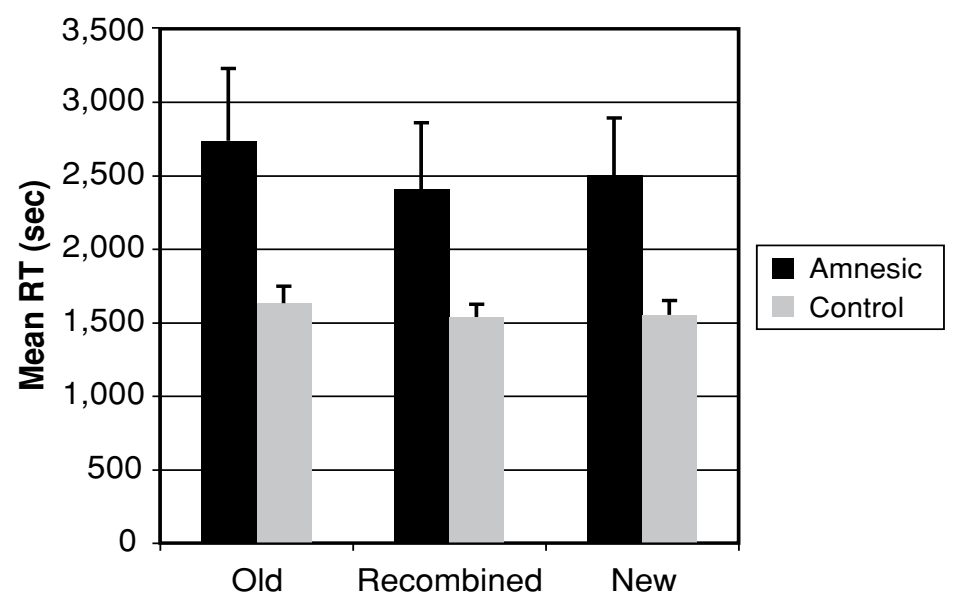

Figure 4. Experiment 2A: Mean decision latencies (RTs) for unrelated word pairs as a function of test condition. 
Their memory functioning was severely compromised, as indicated by a mean General Memory Index of 60.1, a mean Visual Delay Index of 64.5, and a mean Auditory Delay Index of 63.4.

The control group consisted of 5 individuals with a history of alcoholism and 10 individuals with no known history of alcoholism. The control group had a mean age of 58.4 years, with a mean education of 14.8 years, and a mean WAIS-III verbal IQ score of 104.6. The control and amnesic participants did not differ significantly in age, education, or verbal IQ (all $t \mathrm{~s}<1$ ).

Materials and Procedure. The stimuli and procedure were identical to those in Experiment 2A, with the exception of the instructions given during the test phase. The participants were asked to respond "old" when the two words presented on the screen had been seen as a pair during the study phase and to respond "new" when the words had not been seen as a pair during the study phase. The participants were tested using the same study and test lists as those in Experiment 2A. A minimum of 14 weeks had passed since their participation in that experiment.

\section{Results}

Figure 5 presents the proportion of word pairs endorsed as old by amnesic and control participants in the various test conditions. The amnesic group endorsed fewer old pairs than did the control group (hits) but more recombined and more new pairs (false alarms). These impressions were confirmed in an ANOVA of the arcsinetransformed data, which revealed a significant effect of condition $[F(1,26)=181.71, p<.01]$ and a significant group $\times$ condition interaction $[F(1,26)=14.83, p<.01]$. Post hoc comparisons indicated a reduced hit rate for old pairs in amnesia $[t(26)=4.79, p<.01]$ and an enhanced false alarm rate for new pairs $[t(26)=2.16, p<.05]$. Group differences in false alarms to recombined pairs did not reach significance. A direct measure of associative memory, calculated as the difference between the proportion of old and recombined pairs endorsed, revealed a significant impairment in associative memory in the amnesic group $[t(26)=4.0, p<.01]$.

\section{GENERAL DISCUSSION}

This study evaluated the performance of amnesic patients on two tasks of conceptual priming for novel associations, with the goal of further characterizing the role of the hippocampus in relational memory. Although previous studies have shown preserved priming for novel perceptual associations in amnesia (Gabrieli et al., 1997; Goshen-Gottstein et al., 2000; Moscovitch et al., 1986), we hypothesized that priming for novel conceptual associations would be impaired. This hypothesis was only partially confirmed. Amnesic patients showed impaired associative priming in a category exemplar generation task in which contextual information associated with a target could increase the likelihood of target generation, but they showed intact associative priming in a relatedness judgment task, in which priming was manifest as longer latencies for old than for recombined pairs of unrelated words. ${ }^{3}$ Intact associative priming in the relatedness judgment task was seen, notwithstanding a striking impairment in explicit memory for the same associations.

An important question raised by these findings concerns how differences in task demands may account for these different outcomes. In the relatedness judgment task (a verification task), both elements are presented at test, and the only requirement for task performance is that the complete configuration be processed. Priming is a manifestation of the ease of processing that is conferred by recent exposure to the configuration of elements - in this case, leading to slower rejection of the items as being related. Priming in this task, therefore, merely requires coactivation of elements recently processed together. By contrast, in the category exemplar generation task, only one of the constituent elements (the context word) is presented at test, and priming depends on that constituent cuing rein-

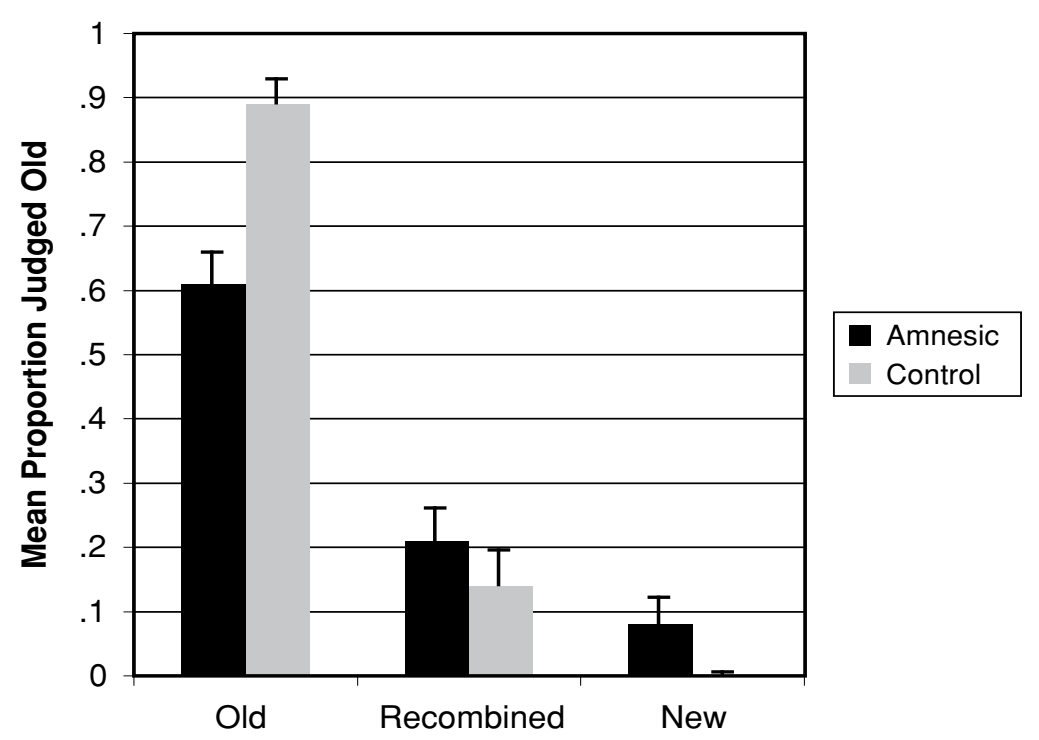

Figure 5. Experiment 2B: Mean proportion of word pairs endorsed as old as a function of test condition. 
statement of the rest of the configuration. Thus, priming in this task requires the reconstruction of the stimulus configuration on the basis of partial information.

We hypothesize that priming through coactivation and priming through reconstruction depend on different kinds of representations. In the verification task, a rigidly bound representation of the study configuration, without preservation of the individual status of the constituent elements, may be sufficient for priming. In contrast, in the generation task, the elements need to be linked flexibly into a representation that preserves the integrity of the constituents. Eichenbaum and colleagues (Eichenbaum \& Cohen, 2001; Eichenbaum, Schoenbaum, Young, \& Bunsey, 1997) have argued that these two types of representations (fused vs. relational, in their terminology) have distinct neural substrates and, particularly, that the hippocampus is critical for the creation of relational representations. According to this view, amnesics' impairment in associative priming in the generation task may reflect their inability to create flexible, relational representations.

An alternative way to conceptualize differences between the generation and the verification tasks is with regard to the role of the first constituent of a stimulus configuration at test. In the generation task, the first constituent need not be actively processed. Its effect on performance is incidental to the task at hand. In contrast, in the verification task, the first element needs to be actively processed, as does the second element. It is possible that amnesic patients show intact conceptual priming when both constituents are intentionally processed at test, but not when only one constituent is intentionally processed. Because both constituents were actively processed at study, such a pattern might represent an instantiation of transfer-appropriate processing (Blaxton, 1989; Roediger, Weldon, \& Challis, 1989a).

Of note, both of these interpretations not only account for the pattern of results obtained in the conceptual associative priming paradigms used here, but also can accommodate the results from perceptual associative priming studies. The perceptual identification, lexical decision, and reading paradigms that have been used to evaluate perceptual associative priming are verification tasks in which priming occurs through coactivation (and thus, can be mediated by a fused representation), and all of them also require intentional processing of the two constituent elements at study and at test. Amnesics' preserved priming in these tasks, therefore, is consistent with either hypothesis.

A potentially interesting paradigm that may help distinguish between these two hypotheses in the perceptual domain is the visual search task used by Chun and Phelps (1999). They found that nonamnesic individuals identified a target more quickly when the visual context in which it occurred consisted of a visual array that was repeated across multiple trials, rather than a visual array that was novel. Amnesic patients, in contrast, failed to show this implicit associative effect. In this task, the context as a whole is not processed intentionally, either at initial or at repeated presentation. At the same time, the full visual array is presented at test, and therefore, priming can be supported by a fused representation. Amnesics' impairment in this task, therefore, might be taken as evidence that the status of associative priming in amnesia is better explained with reference to the processing requirements associated with the task than with reference to the kind of representation that supports the effect (fused vs. relational). However, a failure to replicate these findings in amnesic patients with more restricted damage calls into question this suggestion (Manns \& Squire, 2001). Thus, future studies will be needed to evaluate which theoretical framework provides a better account of impaired and preserved new associative priming in amnesia and, by inference, a better understanding of the role of the hippocampus in associative memory.

\section{REFERENCES}

Battig, W. F., \& Montague, W. E. (1969). Category norms for verbal items in 56 categories: A replication and extension of the Connecticut norms. Journal of Experimental Psychology, 80, 1-46.

Blaxton, T. A. (1989). Investigating dissociations among memory measures: Support for a transfer-appropriate processing framework. Journal of Experimental Psychology: Learning, Memory, \& Cognition, 15, 657-668.

Cermak, L. S., Bleich, R. P., \& Blackford, S. P. (1988). Deficits in the implicit retention of new associations by alcoholic Korsakoff patients. Brain \& Cognition, 7, 312-323.

Chun, M. M., \& Phelps, E. A. (1999). Memory deficits for implicit contextual information in amnesic subjects with hippocampal damage. Nature Neuroscience, 2, 844-847.

DaVACHI, L., \& WAGNer, A. D. (2002). Hippocampal contributions to episodic encoding: Insights from relational and item-based learning. Journal of Neurophysiology, 88, 982-990.

Eichenbaum, H. (1999). The hippocampus and mechanisms of declarative memory. Behavioral Brain Research, 103, 123-133.

Eichenbaum, H., \& Cohen, N. J. (2001). From conditioning to conscious recollection. New York: Oxford University Press.

Eichenbaum, H., Schoenbaun, G., Young, B., \& Bunsey, M. (1997). Functional organization of the hippocampal memory system. Proceedings of the National Academy of Sciences, 93, 13500-13507.

Faust, M. E., Balota, D. A., Spieler, D. H., \& Ferraro, F. R. (1999). Individual differences in information-processing rate and amount: Implications for group differences in response latency. Psychological Bulletin, 125, 777-799.

Fleischman, D. A., \& Gabrieli, J. D. E. (1998). Repetition priming in normal aging and Alzheimer's disease: A review of findings and theories. Psychology \& Aging, 13, 88-119.

FrANCIS, W. N., \& KučERA, H. (1982). Frequency analysis of English usage: Lexicon and grammar. Boston: Houghton Mifflin.

Gabrieli, J. D. E., Keane, M. M., Zarella, M., \& Poldrack, R. A. (1997). Preservation of implicit memory for new associations in global amnesia. Psychological Science, 8, 326-329.

Giovanello, K. S., Schnyer, D. M., \& Verfaellie, M. (2004). A critical role for the anterior hippocampus in relational memory: Evidence from an fMRI study comparing associative and item recognition. Hippocampus, 14, 5-8.

Giovanello, K. S., Verfaellie, M., \& Keane, M. M. (2003). Disproportionate deficit in associative recognition relative to item recognition in global amnesia. Cognitive, Affective, \& Behavioral Neuroscience, 3, 186-194.

Goshen-Gottstein, Y., \& Moscovitch, M. (1995a). Repetition priming for newly formed and preexisting associations: Perceptual and conceptual influences. Journal of Experimental Psychology: Learning, Memory, \& Cognition, 21, 1229-1248.

Goshen-Gottstein, Y., \& Moscovitch, M. (1995b). Repetition priming for newly formed associations are perceptually based: Evidence from shallow encoding and format specificity. Journal of Experimental Psychology: Learning, Memory, \& Cognition, 21, 1249-1262.

Goshen-Gottstein, Y., Moscovitch, M., \& Melo, B. (2000). Intact 
implicit memory for newly formed verbal associations in amnesic patients following single study trials. Neuropsychology, 14, 570-578.

GraF, P., \& SCHACTER, D. L. (1989). Unitization and grouping mediate dissociations in memory for new associations. Journal of Experimental Psychology: Learning, Memory, \& Cognition, 15, 930-940.

Graf, P., Shimamura, A. P., \& Squire, L. R. (1985). Priming across modalities and across category levels: Extending the domain of preserved function in amnesia. Journal of Experimental Psychology: Learning, Memory, \& Cognition, 11, 385-395.

Henke, K., Buck, A., Weber, B., \& Wieser, H. G. (1997). Human hippocampus establishes associations in memory. Hippocampus, 7 , 249-256.

Henke, K., Weber, B., Kneifel, S., Wieser, H. G., \& Buck, A. (1999). Human hippocampus associates information in memory. Proceedings of the National Academy of Sciences, 96, 5884-5889.

Keane, M. M., Gabrieli, J. D. E., Monti, L., Fleischman, D. A., CanTOR, J. M., \& Noland, J. S. (1997). Intact and impaired conceptual memory processes in amnesia. Neuropsychology, 11, 59-69.

Manns, J. R., \& SQuire, L. R. (2001). Perceptual learning, awareness, and the hippocampus. Hippocampus, 11, 776-782.

Mayes, A. R., \& Gooding, P. (1989). Enhancement of word completion priming in amnesics by cueing with previously novel associates. Neuropsychologia, 27, 1057-1072.

Moscovitch, M., Winocur, G., \& McLachlan, D. (1986). Memory as assessed by recognition and reading time in normal and memoryimpaired people with Alzheimer's disease and other neurological disorders. Journal of Experimental Psychology: Learning, Memory, \& Cognition, 6, 1068-1074.

Musen, G., \& SQuire, L. (1993). Implicit learning of color-word associations using a Stroop paradigm. Journal of Experimental Psychology: Learning, Memory, \& Cognition, 19, 789-798.

O'ReILly, R. C., \& RUDY, J. W. (2001). Conjunctive representations in learning and memory: Principles of cortical and hippocampal function. Psychological Review, 108, 311-345.

Roediger, H. L., III, Srinivas, K., \& Weldon, M. S. (1989). Dissociations between implicit measures of retention. In S. Lewandowsky, J. C. Dunn, \& K. Kirsner (Eds.), Implicit memory: Theoretical issues (pp. 67-84). Hillsdale, NJ: Erlbaum.

Roediger, H. L., III, Weldon, M. S., \& Challis, B. H. (1989). Explaining dissociations between implicit and explicit measures of retention: A processing account. In H. L. Roediger, III \& F. I. M. Craik (Eds.), Varieties of memory and consciousness (pp. 3-41). Hillsdale, NJ: Erlbaum.

Schacter, D. L., Bowers, J., \& Booker, J. (1989). Intention, awareness, and implicit memory: The retrieval intentionality criterion. In S. Lewandowsky, J. C. Dunn, \& K. Kirsner (Eds.), Implicit memory: Theoretical issues (pp. 47-65). Hillsdale, NJ: Erlbaum.

SCHACTER, D. L., \& GRAF, P. (1986a). Effects of elaborative processing on implicit and explicit memory for new associations. Journal of Experimental Psychology: Learning, Memory, \& Cognition, 12, 432-444.

Schacter, D. L., \& Graf, P. (1986b). Preserved learning in amnesic patients: Perspectives from research on direct priming. Journal of Clinical \& Experimental Neuropsychology, 8, 727-743.

Shimamura, A. P., \& Seuire, L. R. (1989). Impaired priming of new associations in amnesia. Journal of Experimental Psychology: Learning, Memory, \& Cognition, 15, 721-728.

Srinivas, K., CulP, D., \& RaJaram, S. (2000). On associations between computers and restaurants: Rapid learning of new associations on a conceptual implicit memory test. Memory \& Cognition, 28, 900-906.

Turriziani, P., Fadda, L., Caltagirone, C., \& Carlesimo, G. A. (2004). Recognition memory for single items and for associations in amnesic patients. Neuropsychologia, 42, 426-433.

Vaidya, C. J., Gabrieli, J. D. E., Keane, M. M., Monti, L. A., Gutierrez- Rivas, H., \& Zarella, M. M. (1997). Evidence for multiple mechanisms of conceptual priming on implicit memory tests. Journal of Experimental Psychology: Learning, Memory, \& Cognition, 23, 1324-1343.

Verfaellie, M., \& Keane, M. M. (2001). Scope and limits of implicit memory in amnesia. In B. De Gelder, E. De Haan, \& C. Heywood (Eds.), Unconscious minds (pp. 151-162). Oxford: Oxford University Press.

Verfaellie, M., \& Keane, M. M. (2002). Impaired and preserved memory processes in amnesia. In L. R. Squire \& D. L. Schacter (Eds.), Neuropsychology of memory (3rd ed., pp. 35-46). New York: Guilford.

WeChSLER, D. (1997a). Wechsler Adult Intelligence Scale-III. San Antonio, TX: Psychological Corporation.

WeChSLER, D. (1997b). Wechsler Memory Scale-III. San Antonio, TX: Psychological Corporation.

Yonelinas, A. P., Hopfinger, J. B., Buonocore, M. H., Kroll, N. E. A., \& BAYNES, K. (2001). Hippocampal, parahippocampal and occipitaltemporal contributions to associative and item recognition memory: An fMRI study. NeuroReport, 12, 359-363.

\section{NOTES}

1. One procedural difference between the two experiments is that our rating task consisted of rating how believable the information was that was conveyed in each sentence, whereas in Schacter and Graf (1986a), it consisted of rating how meaningfully each sentence related the two target words. It is possible that our task encouraged the participants to make more elaborate connections with preexisting knowledge, thus leading to better explicit memory for the word pair (see also Graf \& Schacter, 1989).

2. Interpretation of the trend toward higher associative priming in amnesic patients than in controls is complicated by scaling effects. To take into account differences in reaction time between patients and controls, each individual's scores were $z$-transformed, as advocated by Faust, Balota, Spieler, and Ferraro (1999). Analysis of the $z$-transformed scores revealed a mean effect of condition but no group $\times$ condition interaction, suggesting that the magnitude of associative priming was similar in the two groups when baseline reaction time differences were taken into account.

3. Because the amnesic participant samples in Experiments 1A and $2 \mathrm{~A}$ were not identical, the question arises as to whether differences in the pattern of performance across tasks might be due to differences in the amnesic participants across experiments. To eliminate this possibility, we analyzed the results from the subset of amnesic patients $(n=11)$ who participated in both Experiments 1A and 2A. The findings for both experiments were identical to those obtained in the full patient groups, ruling out differences in amnesic samples as the basis for differences in the status of associative priming across tasks.

(Manuscript received June 20, 2005; revision accepted for publication January 19, 2006.) 